\title{
‘HE THAT NO GOOD CAN’: AN UNRECORDED COPY OF A MIDDLE ENGLISH
}

\section{Proverb}

Oxford, Bodleian Library, MS Digby 99 is a late fourteenth-century manuscript copied in one hand on paper. It contains a copy of the synodal statutes of William Raleigh, followed by an idiosyncratic copy of the Middle English poem The Prick of Conscience. ${ }^{1}$ The scribe identifies himself in his colophon as 'Frater Iohannes stanys canonicus Thetfordie'. ${ }^{2}$ As the available descriptions indicate, this is a fascinating book, and its copying, provenance and use merit more detailed treatment elsewhere. ${ }^{3}$ For the present purpose, however, the key text in the book is a copy of Supplement to the Index of Middle English Verse 1162.8 in a fifteenth-century hand-not the hand of the scribe-in the bottom margin of one page. ${ }^{4}$ To my knowledge this instance has not previously been recorded. ${ }^{5}$ It reads:

\footnotetext{
${ }^{1}$ The statutes have been edited, from MS Digby 99, in F. M. Powicke and C. R. Cheney (eds), Councils and Synods, With Other Documents Relating to the English Church, A.D. 1205-1313, 2 vols (Oxford, 1964), I, 342-64. The best edition of The Prick of Conscience is Ralph Hanna and Sarah Wood (eds), Richard Morris's Prick of Conscience: A Corrected and Amplified Reading Text, EETS o.s. 342 (Oxford, 2013).

${ }^{2}$ MS Digby 99, f. $156^{\mathrm{v}}$.

${ }^{3}$ Robert E. Lewis and Angus McIntosh, A Descriptive Guide to the Manuscripts of the Prick of Conscience, Medium Aevum Monographs n.s. 12 (Oxford, 1982), 98-9; W. D. Macray, R. W. Hunt and A. G. Watson, Bodleian Library Quarto Catalogues: IX, Digby Manuscripts (Oxford, 1999), I, 113 and II, 55. Hunt and Watson suggest that the Stanys named in the colophon at $\mathrm{f}$. $156^{\mathrm{v}}$ is the same as the 'Stanys / monachum westminestrij' who appears in Oxford, Balliol College, MS 264 (f. 98 r), but this is unlikely given the gap between the likely period of production of MS Digby 99, the late fourteenth century, and the Westminster Stanys's date of profession, 1462/3: E. H. Pearce, The Monks of Westminster (Cambridge, 1916), 159, quoted in R. A. B. Mynors, Catalogue of the Manuscripts of Balliol College, Oxford (Oxford, 1963), 284.

${ }^{4}$ MS Digby 99, f. $108^{\mathrm{v}}$.

5 The text appears in Rossell Hope Robbins and John L. Cutler, Supplement to the Index of Middle English Verse (Lexington, 1965) (hereafter 'SIMEV'), as item 1162.8; in J. Boffey and A. S. G. Edwards, A New Index of Middle English Verse (London, 2005) (hereafter 'NIMEV'), as a reference to W. A. Ringler, Jr., Bibliography and Index of English Verse in Manuscript 1501-1558 (London: 1992), item TM 547; in L. R. Mooney, D. W. Mosser, and E. Solopova, with D. H. Radcliffe, 'The DIMEV: An Open-Access, Digital Edition of the Index of Middle English Verse', <http://www.cddc.vt.edu/host/imev/>, accessed 13 April 2015, as item 1891.1; and in Bartlett Jere Whiting, Proverbs, Sentences and Proverbial Phrases: From English Writings Mainly before 1500 (Cambridge, MA, 1968), as item G351. None of these sources include MS Digby 99.
} 


$$
\begin{aligned}
& \text { He that no good can } \\
& \text { nore none wylle leryn } \\
& \text { and he neuer thryve } \\
& \text { ho may hem warvne }
\end{aligned}
$$

The hand is essentially modelled on anglicana in its ductus and most of its letterforms, though it has the single-compartment secretary a, as was common in fifteenth-century anglicana, and alternates between an anglicana $\mathbf{w}$ for 'wylle' and an open secretary w for 'warvne'. (I have no explanation for the use of the form 'warvne' for 'warne', unless it is a mistake.) The sample size is very small but I would tentatively date this writing to the second half of the fifteenth century. It shares some suggestive common features with some of the writing in the collection of songs and carols which is now Bodleian Library, MS Eng. poet. e.1, although it is not identical to any of the hands in that manuscript. ${ }^{7}$ For example, the hand that writes $11^{\mathrm{r}}-48^{\mathrm{r}}$ shares the approach-stroke on word-initial $\mathbf{m}$, the rightwards lean of the looped ascender of $\mathbf{h}$ and the leftwards curve of the stem of $\mathbf{t}$. The hand that copies the proverb in MS Digby 99 also displays a hint of the rightwards flick at the bottom of the descender of $\mathbf{y}$ which is more pronounced in MS Eng. poet. e.1. The first hand's activity in MS Eng. poet. e.1 probably dates from the end of the fifteenth century, and it has been suggested that its dialect is locatable to South-West Norfolk; dialect is not cast-iron evidence for a manuscript’s place of production and reading,

\footnotetext{
${ }^{6}$ Here and below, abbreviations are silently expanded, including the abbreviation marks for '-e' in 'nore' and 'wylle', which might be otiose strokes.

${ }^{7}$ On this book and its contents see Daniel Wakelin, 'The Carol in Writing: Three Anthologies from Fifteenth-Century Norfolk', Journal of the Early Book Society, ix (2006), 25-49.
} 
but in the absence of evidence to the contrary this localization might put this manuscript in the same part of Norfolk as Thetford, where MS Digby 99 was copied. ${ }^{8}$ The text is a proverbial couplet, although here it is copied as a xaxa stanza. A four-part brace has been added on the right in text-ink; since the brace braces every line it must denote verse in general, or the idea of rhyme, rather than the actual rhyme-scheme. The scribe may have chosen this arrangement simply because the pages of MS Digby 99 are not very wide.

Where could this book have been when this saw was added to it? If the hand does date from the second half of the fifteenth century, then the book had probably passed from Stanys's hands when the proverb was written into it. There are a number of names written into the book. Probably the earliest is 'margarete salis de methe wolde', in a late fifteenth-century hand; Methwold is a Norfolk village around twenty-five miles from Thetford. ${ }^{9}$ Perhaps, then, this book had found its way into lay ownership by the time the proverb was added. Besides names, the pages of MS Digby 99 contain a number of other marginal pen trials and doodles, none clearly connected to the text, and it seems plausible to imagine the book existing in a household where it was read devotionally and didactically but also subjected to a certain amount of marginal scribbling — not-reading, perhaps at the hands of children.

Is there a connection between this proverbial couplet and The Prick of Conscience? There is no clear link to the content of the poem at this specific opening in the book, which discusses how parents will be held to account for the keeping of their children at the Day of Doom, and then the necessity of guarding one's body

\footnotetext{
${ }^{8}$ McIntosh and others, A Linguistic Atlas of Late Medieval English (Aberdeen, 1986), I, 148.

${ }^{9}$ MS Digby 99, f. $1^{\mathrm{r}}$.
} 
against sin as one would guard a castle. ${ }^{10}$ The proverb is not, then, necessarily a specific response to this particular passage, but it resonates with the poem's stated purpose to offer knowledge to the ignorant and fear to the unmotivated, and it recalls the prologue:

In gret peryle of soule is pat man.

Pat hath wit and mende and no good can.

And wyl not lere for to knawe.

pe werkys of god and of godys lawe. ${ }^{11}$

This is not the only moment at which idea of the person who either 'good can' or 'no good can' enters The Prick of Conscience, for the redactor who rewrote the text to produce its Southern Recension inserted an additional reference to 'he pat any goode can'. ${ }^{12}$ The proverb is unlikely to be a quotation. Rather, the proverb and The Prick of Conscience probably draw on a shared body of sayings. The distinction between those who 'good can' and those who 'no good can' may have been a proverbial element in Middle English religious instructional writing. Perhaps, then, the proverb’s presence here does indicate the book’s continuing later life in the world of religious instruction, and while it may not be directly a response to the text it originates in the same body of thought.

Previously the only known witness to this text was the famous early sixteenth-century so-called 'commonplace book' of Richard Hill, a member of the

\footnotetext{
${ }^{10}$ MS Digby 99, ff. 108v-109r contain lines equivalent to Hanna and Wood (eds), ll. 5777-89, 57925817 and 5820-34.

${ }^{11}$ MS Digby 99, f. 11르. ll. 18-21; the equivalents of Hanna and Wood (eds), ll. 161-4.

${ }^{12}$ At the time of writing there is no edition of the Southern Recension, although Jean E. Jost is preparing one based on San Marino, Henry E. Huntington Library, MS HM 125. This quotation comes from the copy in Oxford, Bodleian Library, MS Bodley 423, f. 246v , 5; it also occurs with no substantial variation in MS HM 125, f. 8v , 27; and it is a much-altered equivalent to Hanna and Wood (eds), 1. 510. MS Digby 99 itself is not a Southern Recension copy, but rather a Group IV text of the poem’s ‘Main Version': Lewis and McIntosh, 99.
} 
London Grocers’ Company. In Hill’s book the proverb appears within a collection of proverbs. ${ }^{13}$ It is copied without lineation, and a double virgule indicates the linedivision instead. It reads:

he that no good can nore non will lerne // if he newere thriwe who shallle shalle him warne

Hill's hand is modelled on secretary script, but here it is rapid, with few concessions to readability. Indeed, he uses a rudimentary cipher which replaces $\mathbf{a}, \mathbf{i}, \mathbf{e}, \mathbf{o}$ and $\mathbf{w}$ with other symbols. Since the same leaf's recto contains the table explaining this cipher, it is likely to be personal amusement rather than serious concealment-it might mark the text as something which Hill engaged with slightly playfully. ${ }^{14}$ In Hill's book the proverb is integrated into a larger list of wise sayings, most taking up only one line and unrhymed. They were probably copied and perhaps read as a unit. The couplet in this manuscript might have been read as a component of a larger whole like the lyrics within sermons which indices of Middle English verse also record. That said, although Hill did not lineate $\underline{\text { SIMEV }} 1162.8$ as verse, using a double virgule to indicate the line-break instead, he did add a brace in text-ink to the right, distinguishing it from the surrounding prose proverbs.

The codicological contexts in which these two instances of the proverb appear are therefore unlike each other in some ways. Stanys's book was produced

\footnotetext{
${ }^{13}$ Oxford, Balliol College, MS 354, f. $191^{\mathrm{v}}$ or p. 402 (the manuscript has both foliation and pagination), ll. 40-1. The proverb was printed from this manuscript in Roman Dyboski (ed.), Songs, Carols and Other Miscellaneous Poems from the Balliol MS. 354, Richard Hill's CommonplaceBook, EETS e.s. 101 (London, 1907), 129. Dyboski writes that 'The MS. has warm with the gloss or warne rather', but as I read it the manuscript has 'warne', with the stroke which Dyboski read as the last stroke of $\mathbf{m}$ in fact being the first stroke of Hill's symbol for e. I can find no sign of the gloss. 14 There are three cipher tables on MS 354, f. $191^{\mathrm{r}}$ (or p. 401). The one put to use on $\mathrm{f} .191^{\mathrm{v}}$ is the third and simplest one.
} 
significantly earlier, by a canon, and appears to have remained in an East Anglian context in which, at some point, a later reader added the proverb in the margin.

Richard Hill's book was produced and presumably read in a metropolitan, mercantile context, and Hill copied the proverb himself, into the main column. However, both books are personal rather than institutional. The main texts in Digby 99 may be fairly monumental, but one tipped-in leaf contains the Paternoster, the Ave and a creed in Middle English, and on its reverse three (appropriately pious) Latin charms against sickness, all probably copied in Stanys's hand. ${ }^{15}$ So this book preserves evidence of personal, 'notebook' text storage not unlike that in Balliol MS 354. Comparison between the two witnesses for SIMEV 1168.2 can thus slightly enhance our picture of the textual traffic between London and East Anglia either side of 1500. The closeness of some of that textual traffic is underlined by the fact that there are twenty texts which appear in both Balliol MS 354 and MS Eng poet e.1, the book of carols containing some handwriting not unlike that of the proverb in MS Digby $99 .^{16}$

A slightly earlier witness for this text also rescues it from its rough treatment during different reference tools' necessary but awkward periodisation of 'Middle English verse'. The Index of Middle English Verse took 1500 as its terminus ad quem and so texts only then known in Hill's sixteenth-century book were excluded, although the manuscript appears in entries for texts which were also known in earlier copies. ${ }^{17}$ The Supplement extended its reach to $c .1550$ and so included 'He that no

\footnotetext{
${ }^{15}$ MS Digby 99, f. 139a ${ }^{\mathrm{r}-\mathrm{v}}$. The first charm was widespread and is discussed, using other examples, in Don Skemer, Binding Words: Textual Amulets in the Middle Ages (Philadelphia, 2006), 106-7. Lewis and McIntosh suggest (at 98) that these are in a different hand, but both hands share many features: both exhibit the same bifurcation in the ascenders of $\mathbf{b}$ and $\mathbf{l}$, and the same unpredictable and apparently meaningless variation between horned and hornless e, for example.

16 The shared texts are Carleton Brown and Rossell Hope Robbins, The Index of Middle English Verse (New York, 1943) (hereafter 'IMEV'), items 112, 375, 889, 890, 1219, 1362, 1471, 1485, 1914, 2090, 2098, 3171, 3307, 3596, 3627, 3736, 3776, 3820, 3852 and 3999.

${ }^{17} \underline{\mathrm{IMEV}}$, ix.
} 
good can'. ${ }^{18}$ Aided by W. A. Ringler's work on printed and manuscript verse in the first half of the sixteenth century, the New Index returned to c. 1500, so that SIMEV 1162.8 receded from the sight of Middle English specialists behind a reference to Ringler. ${ }^{19}$ In the Digital Index, which runs to $c .1550$, the proverb returned again, though this time with a different reference number, 1891.1. The oscillation of SIMEV 1162.8 in and out of the position of 'Middle English verse' is a salutary reminder that each of these useful reference tools has a distinct and individual scope. But, with the text now known in a copy which probably dates from before $c$. 1500, and perhaps also in the light of its proverbial resonance with the widely successful

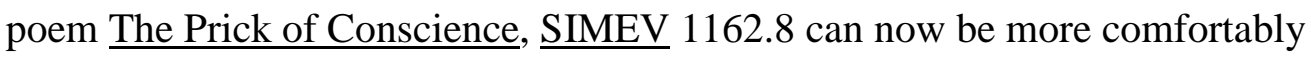
regarded as Middle English verse wherever one draws the line.

DANIEL SAWYER

St Hilda’s College, Oxford

${ }^{18}$ SIMEV, xiv-xviii.

${ }^{19}$ NIMEV, xii; Ringler, English Verse in Manuscript, and Ringler, Bibliography and Index of English Verse Printed 1476-1558 (London, 1988). 